\title{
IL-22 is required for Th17 cell-mediated pathology in a mouse model of psoriasis-like skin inflammation
}

\author{
Hak-Ling Ma, ${ }^{1}$ Spencer Liang, ${ }^{1}$ Jing Li, ${ }^{2}$ Lee Napierata, ${ }^{1}$ Tom Brown, ${ }^{3}$ Stephen Benoit, ${ }^{1}$ \\ Mayra Senices, ${ }^{1}$ Davinder Gill, ${ }^{2}$ Kyriaki Dunussi-Joannopoulos, ${ }^{1}$ Mary Collins, ${ }^{1}$ \\ Cheryl Nickerson-Nutter, ${ }^{1}$ Lynette A. Fouser, ${ }^{1}$ and Deborah A. Young ${ }^{1}$ \\ 1Inflammation and 2Biological Technologies, Wyeth Research, Cambridge, Massachusetts, USA \\ ${ }^{3}$ Drug Safety and Metabolism, Wyeth Research, Andover, Massachusetts, USA.
}

\begin{abstract}
Psoriasis is a chronic skin disease resulting from the dysregulated interplay between keratinocytes and infiltrating immune cells. We report on a psoriasis-like disease model, which is induced by the transfer of $\mathrm{CD}^{+}{ }^{+} \mathrm{CD} 45 \mathrm{RB}^{\mathrm{hi}} \mathrm{CD25}^{-}$cells to pathogen-free scid/scid mice. Psoriasis-like lesions had elevated levels of antimicrobial peptide and proinflammatory cytokine mRNA. Also, similar to psoriasis, disease progression in this model was dependent on the p40 common to IL-12 and IL-23. To investigate the role of IL-22, a Th17 cytokine, in disease progression, mice were treated with IL-22-neutralizing antibodies. Neutralization of IL-22 prevented the development of disease, reducing acanthosis (thickening of the skin), inflammatory infiltrates, and expression of Th17 cytokines. Direct administration of IL-22 into the skin of normal mice induced both antimicrobial peptide and proinflammatory cytokine gene expression. Our data suggest that IL-22, which acts on keratinocytes and other nonhematopoietic cells, is required for development of the autoreactive Th17 cell-dependent disease in this model of skin inflammation. We propose that IL-22 antagonism might be a promising therapy for the treatment of human psoriasis.
\end{abstract}

\section{Introduction}

Psoriasis is a common, chronic autoimmune disease of the skin, which affects approximately $2 \%$ of the general population. The lesions are characterized by red, scaly, raised plaques at different body sites. Histologically, psoriasis is defined by thickening of the epidermis (acanthosis) due to increased proliferation of keratinocytes, epidermal rete peg formation (downward papillary projections of the epidermis), and parakeratosis (retention of keratinocyte nuclei in the stratum corneum) as well as inflammatory cell infiltrates in the epidermis and dermis (1). Psoriasis does not exist as a spontaneously occurring disease in the skin of animals other than humans. Although some features of psoriasis have been induced in mouse skin by genetic or immune manipulations, these previously described models do not have the full histopathological or immunological features of psoriatic lesions (2-6). In one model, Hong et al. adoptively transferred $\mathrm{CD} 4{ }^{+} \mathrm{CD} 45 \mathrm{RB}{ }^{\text {hi }} \mathrm{T}$ cells into scid/scid recipient mice. Disease severity and incidence in this model were mild and improved by coadministration of IL-12 and LPS during disease induction (7). We have validated this model and developed it further by adoptively transferring $C D 4^{+} \mathrm{CD} 45 \mathrm{RB}{ }^{\text {hi }}$ $\mathrm{T}$ cells depleted of $\mathrm{CD} 25^{+}$regulatory cells into scid/scid recipient mice. Affected mice developed scaly and raised skin plaques with certain microscopic characteristics resembling human psoriasis.

Although the exact cause of psoriasis is unknown, the data suggest that this disease is caused by a dysregulated interplay between keratinocytes and inflammatory cell infiltrates. This dysregulation results in the production of inflammatory cytokines and chemokines that

Conflict of interest: H. Ma, L. Napierata, S. Benoit, M. Senices, D. Gill, K. DunussiJoannopoulos, M. Collins, C. Nickerson-Nutter, L. Fouser, and D.A. Young are employees of Wyeth Research and hold options of Wyeth stock.

Citation for this article: J. Clin. Invest. 118:597-607 (2008). doi:10.1172/JCI33263. facilitate the development of the disease pathology (4). Recent studies have highlighted a role for the Th17 cytokine network, including IL-23 and IL-22, in mediating cutaneous skin inflammation $(8,9)$. IL-23, a cytokine produced by macrophages and DCs, drives the expansion of Th17 cells that have differentiated from naive $T$ cells in the presence of IL- 6 and TGF- $\beta$ (10-13). Injection of IL-23 into the skin triggers a cutaneous inflammatory reaction in wild-type mice, but considerably less of a reaction in IL-22-deficient mice, suggesting that IL-22 is required to mediate inflammation in response to IL-23 (9). IL-22 is an effector cytokine that is made predominantly by Th17 cells and to some extent by activated Th1, $\gamma \delta$ T cells, NK cells, CD8 ${ }^{+} \mathrm{T}$ cells, and monocytes $(9,13,14)$. IL-22 signals through a distinct receptor complex, IL-22R/IL-10R2, which is expressed on a variety of epithelial tissues but not on circulating immune cells. In further support of its role in skin inflammation, IL-22 mediates human keratinocyte hyperplasia ex vivo (15). Elevated IL-22 protein and gene transcripts are found in the serum and skin lesions of psoriatic patients, respectively, and correlate with the severity of the disease (16). This evidence strongly suggests that IL-22 plays a critical role in the pathogenesis of psoriasis. We show that, similar to human psoriasis, disease progression in our model is also IL-12/23p40 dependent. We further demonstrate that IL-22 neutralization alone is sufficient to prevent disease progression in this model.

\section{Results}

Coadministration of LPS and IL-12 enhances disease progression and Th1 cytokine gene expression in the lesional tissue. Previous data have shown that transfer of BALB $/ \mathrm{c} \mathrm{CD} 4^{+} \mathrm{CD} 45 \mathrm{RB}^{\text {hi }} \mathrm{T}$ cells alone into $\mathrm{CB} 17$ scid/scid recipient mice leads to the development of psoriaform lesions. Low disease incidence (38\%) and mild disease expression were observed in these models $(7,17)$. Both disease severity and incidence were improved by coadministration of IL-12 and LPS. Lymphocytes 


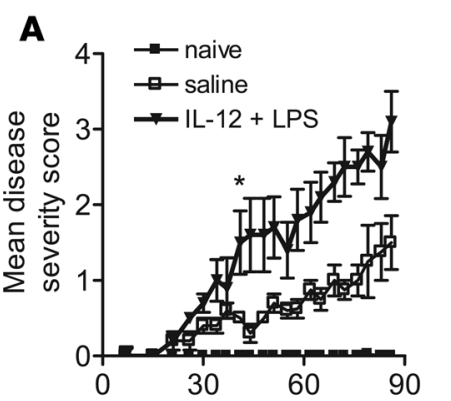

Days post adoptive transfer
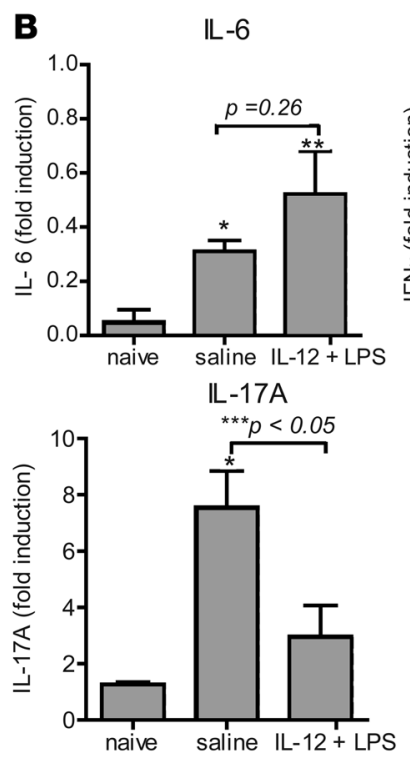
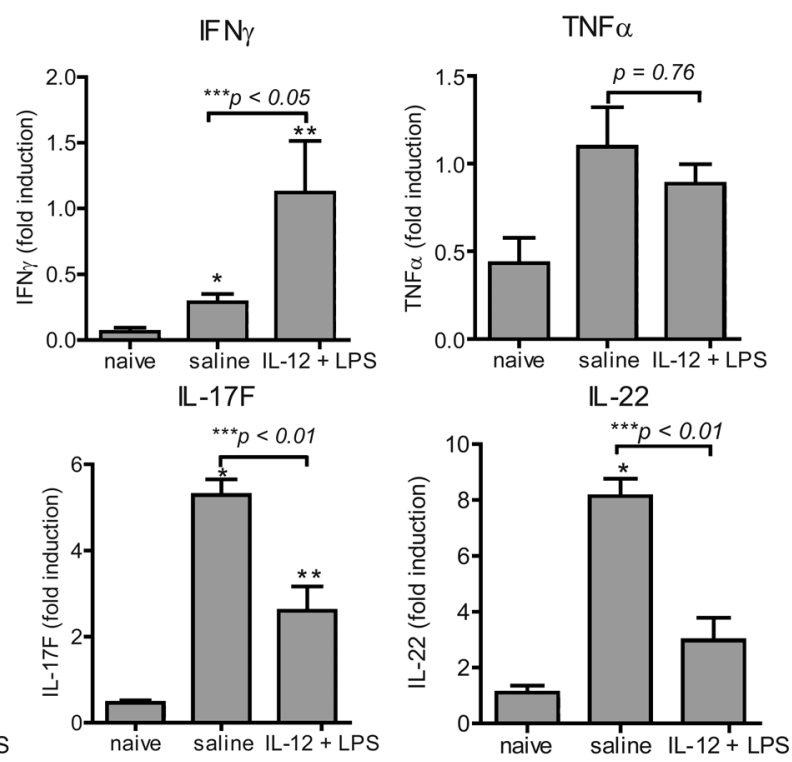

Figure 1

Coadministration of IL-12 and LPS enhances the development of skin lesions in a CD4 ${ }^{+}$CD 45 RB ${ }^{\text {hi }}$ adoptive transfer model. (A) Disease progression in CB17 scid/scid recipient mice with or without (naive) adoptive transfer of $4 \times 10^{5} \mathrm{CD} 4{ }^{+} \mathrm{CD} 45 \mathrm{RB}{ }^{\text {hi }}$ sorted cells. The recipient mice with cell transfer were treated with saline or IL-12 (10 ng) plus LPS $(20 \mu \mathrm{g})$ (i.p.) on day 1 and saline or IL-12 (10 ng) on day 3 (i.p.). ${ }^{*} P<0.05$ starting from day 37 between the saline-treated group and the IL-12/LPS-treated group, both with cell transfer. (B) RNA was purified from an ear biopsy of each mouse within a group at the end of the study and evaluated by quantitative RT-PCR for the indicated cytokines. Results are reported as group means \pm SEM, with $n=10$ for each group. Data are representative of at least 2 independent experiments. ${ }^{*} P<0.05$ between no-treatment group (naive) and saline-treated group with cell transfer; ${ }^{* *} P<0.05$ between no-treatment group (naive) and LPS plus IL-12-treated group with cell transfer; ${ }^{* \star *} P$ value between saline and LPS plus IL-12 treated group is indicated.

isolated from the lesional skin expressed high levels of IFN- $\gamma$ and TNF- $\alpha$ and low levels of IL-4 upon restimulation in vitro, suggesting that Th1 cells play an important role in this model.

Consistent with prior reports, we found that treatment of adoptively transferred recipient mice with IL-12 and LPS significantly increased disease severity (Figure 1A). Mice began to develop psoriatic-like lesions about 2 to 3 weeks after the adoptive transfer of $\mathrm{T}$ cells. Significant differences in disease severity between mice treated with saline or IL-12 plus LPS were observed, starting at day 37 after transfer of cells (Figure 1A). At the end of the study, the mean disease severity scores for mice treated with and without IL-12 and LPS were $2.7 \pm 0.4$ and $1.3 \pm 0.4$ respectively. To determine the type of cytokine response in the lesional skin, mouse RNA was extracted for quantitative RT-PCR analysis of various cytokine transcripts. Compared with mice that received no $\mathrm{T}$ cell transfer, mice receiving $\mathrm{CD} 4^{+} \mathrm{CD} 45 \mathrm{RB}{ }^{\text {hi }}$ cells expressed elevated levels of inflammatory cytokine mRNA encoding IL-6, IFN- $\gamma$, TNF- $\alpha$, IL-17A, IL-17F, and IL-22 (Figure 1B). Detection of elevated levels of IL-17A, IL-17F, and IL-22 mRNA in addition to IFN- $\gamma$ implies that both Th1 and Th17 cells are involved in driving disease progression. In addition, mice treated with IL-12 and LPS had significantly elevated IFN- $\gamma$ transcripts with reduced levels of IL-17A, IL-17F, and IL-22 gene expression when compared with mice without IL-12 and LPS treatment (Figure 1B). Taken together, these results suggest that administration of IL-12 and LPS favors a Th1-driven psoriasis-like disease progression, although both Th1 and Th17 cytokine genes are expressed in the lesional sample.

Removal of Tregs enhances development of skin lesions. As CD $4^{+} \mathrm{CD} 25^{+}$ Tregs play an important role in regulating $\mathrm{T}$ cell function (18) and as Tregs from psoriasis patients have been demonstrated to have defective suppressor function ex vivo (19), we hypothesized that Tregs pres- ent in the $\mathrm{CD}^{+} \mathrm{CD} 45 \mathrm{RB}^{\text {hi }}$ population may have dampened disease progression in prior studies $(7,17)$. We first demonstrated that Tregs are present in the $\mathrm{CD} 4{ }^{+} \mathrm{CD} 45 \mathrm{RB}^{\text {hi }}$ population and that approximately $1 \%$ of CD $4{ }^{+} \mathrm{CD} 45 \mathrm{RB}{ }^{\text {hi }} \mathrm{T}$ cells coexpress the CD 25 and Foxp3 markers (Supplemental Figure 1; supplemental material available online with this article; doi:10.1172/JCI33263DS1). To directly evaluate the effect of Treg depletion on disease progression, mice were injected i.p. with either $\mathrm{CD} 4^{+} \mathrm{CD} 45 \mathrm{RB}^{\text {hi }}$ or $\mathrm{CD} 4^{+} \mathrm{CD} 45 \mathrm{RB}^{\text {hi }} \mathrm{CD} 25^{-} \mathrm{T}$ cells. Mice in both groups began to develop psoriatic-like lesions about 2 weeks after the adoptive transfer of T cells. Disease symptoms included erythema and scaling that started in the skin around the ears and eyelids, progressing to the face, neck, and the rest of the body, including back, trunk, legs, paws, and tails (Figure 2A). However, as shown in Figure $2 \mathrm{~B}$, mice receiving $\mathrm{CD} 4{ }^{+} \mathrm{CD} 45 \mathrm{RB}{ }^{\text {hi }} \mathrm{T}$ cells depleted of Tregs developed significantly more severe disease (final mean disease score $=2.9 \pm 0.3$ ) compared with mice receiving CD25 ${ }^{+}$cells (final mean disease score $=1.4 \pm 0.3$ ). Additionally, quantitative RT-PCR for Foxp3 indicated that mice receiving $\mathrm{CD} 4^{+} \mathrm{CD} 45 \mathrm{RB}^{\mathrm{hi}} \mathrm{CD} 25^{-}$cells had significantly less Foxp 3 transcript than those receiving $C D 4^{+} \mathrm{CD} 45 \mathrm{RB}$ hi cells. The presence of a detectable amount of Foxp3 transcript in the $\mathrm{CD} 4{ }^{+} \mathrm{CD} 45 \mathrm{RB}^{\text {hi }} \mathrm{CD} 25^{-}$recipients suggested that Tregs may have been generated in peripheral tissues. The inhibitory effect of the Tregs $\left(\mathrm{CD} 4^{+} \mathrm{CD} 45 \mathrm{RB}^{\mathrm{hi}} \mathrm{CD} 25^{+}\right)$was further investigated in this model by cotransfer of Tregs with $\mathrm{CD} 4^{+} \mathrm{CD} 45 \mathrm{Rb}^{\text {hi }} \mathrm{CD} 25^{-} \mathrm{T}$ cells. As shown in Figure 2B, Tregs suppressed the development of psoriasis in a dosedependent manner. As few as $0.4 \times 10^{5}$ Tregs were able to suppress the disease progression induced by $4 \times 10^{5} \mathrm{CD}^{+} \mathrm{CD} 45 \mathrm{RB}^{\mathrm{hi}} \mathrm{CD} 25^{-} \mathrm{T}$ cells (Figure $2 \mathrm{~B}$ ). Collectively, these studies suggest that $\mathrm{CD} 25^{+} \mathrm{Foxp} 3^{+}$ cells block the development of psoriasis-like skin inflammation in this mouse model. 
A
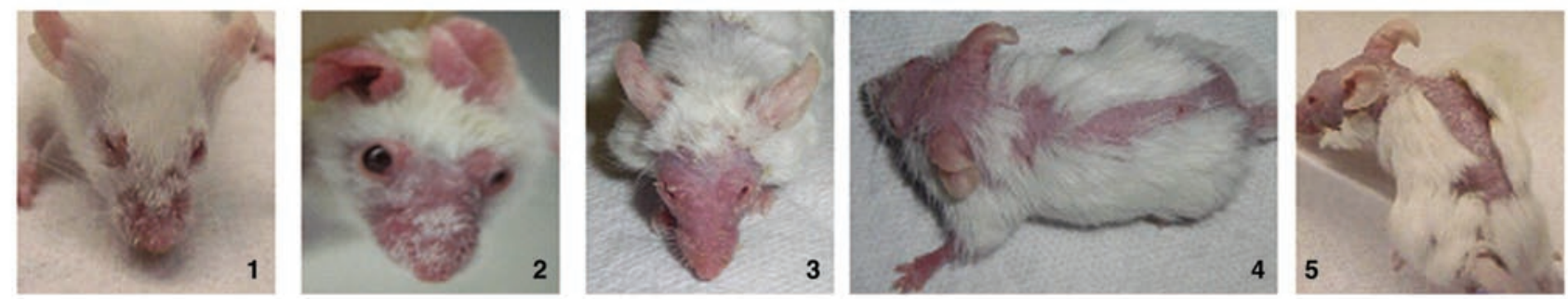

B
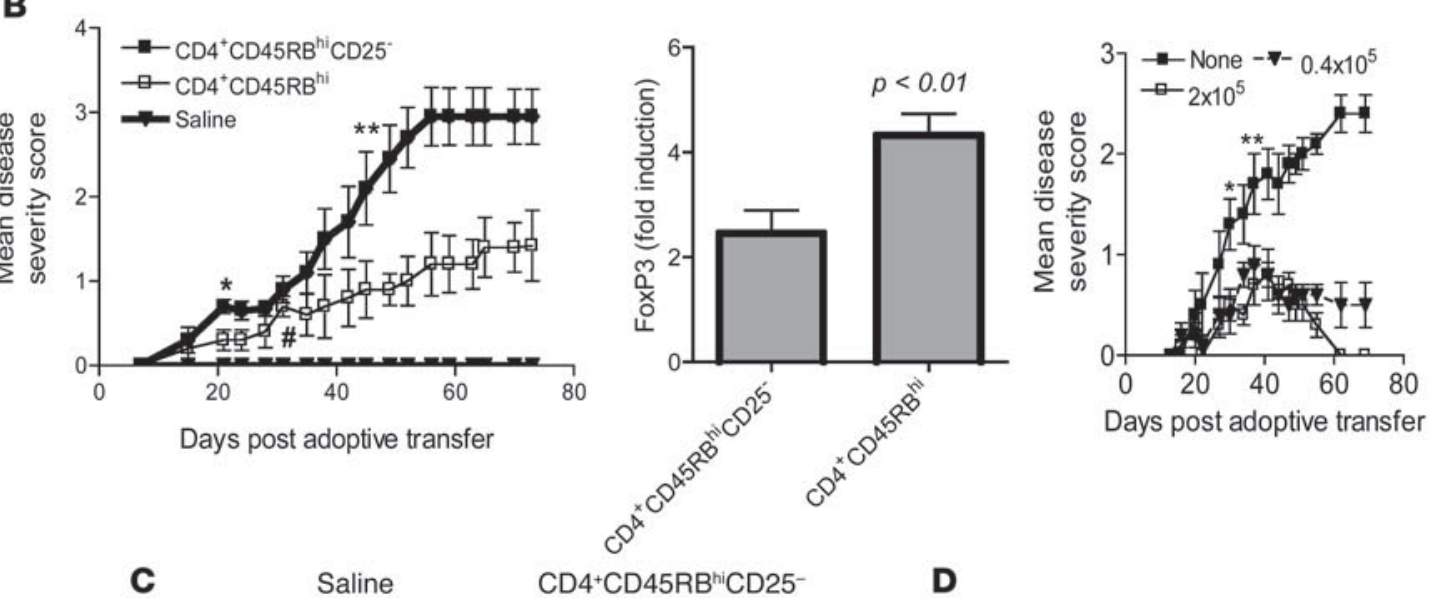

Days post adoptive transfer

Days post adoptive transfer

C
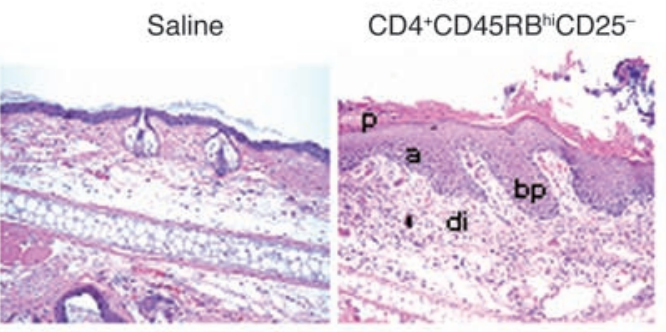

Saline

$\mathrm{CD} 4{ }^{+} \mathrm{CD} 45 \mathrm{RB}^{\text {hi }} \mathrm{CD}^{-} 5^{-}$
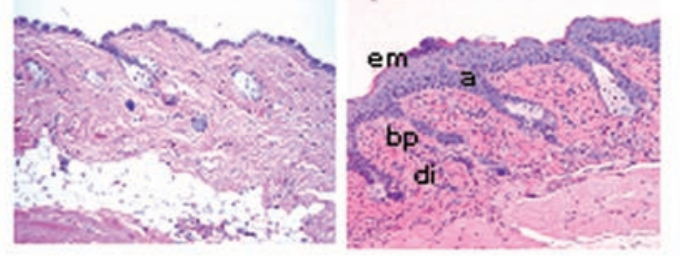

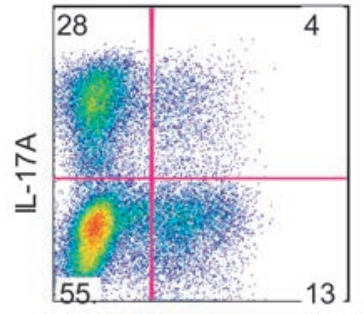

IFNy

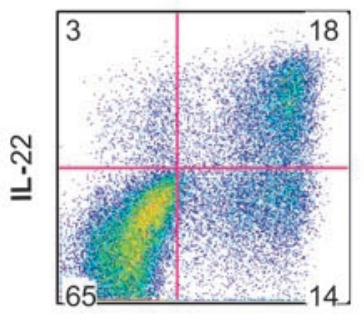

IL-17A
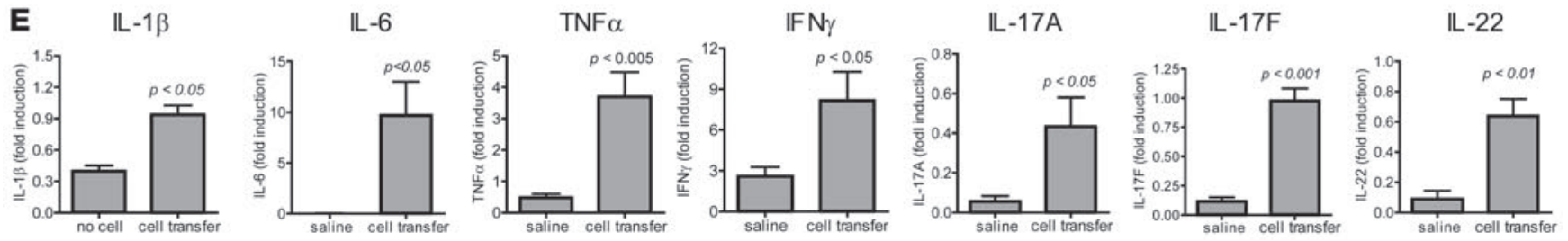

Figure 2

Adoptive transfer of $\mathrm{CD} 4{ }^{+} \mathrm{CD} 45 \mathrm{RB}^{\text {hi }} \mathrm{T}$ cells depleted of $\mathrm{CD} 25^{+}$Tregs enhances the development of skin lesions in scid/scid mice. (A) Representative images of psoriaform lesions in scid/scid mice induced by transfer of CD4+CD45RB ${ }^{\text {hiCD25- }} \mathrm{T}$ cells. The numbers correspond to the given disease severity scores. (B) Mean disease severity in mice after transfer of indicated cells or saline. Left: ${ }^{*} P<0.05$ starting on day 21 between CD4+CD45RB hiCD25- and saline groups; ${ }^{*} P<0.05$ starting on day 35 between CD4+CD45RB ${ }^{\text {hi }}$ and saline; ${ }^{* *} P<0.05$ starting on day 49 between CD4+CD45RB hiCD25- and CD4+CD45RB hi $(n=10)$. Middle: Average Foxp3 gene expression in ear mRNA from indicated groups $(n=10)$. Right: Mean disease severity in scid/scid mice after transfer of T cells with or without indicated Treg numbers. ${ }^{*} P<0.05$ between mice receiving $2 \times 10^{5}$ and no Tregs; ${ }^{* \star} P<0.05$ between $0.4 \times 10^{5}$ and no Tregs. (C) H\&E-stained ear (top panels) and back skin (bottom panels) sections from a mouse transferred with saline or $\mathrm{CD}^{+} \mathrm{CD} 45 \mathrm{RB}^{\mathrm{hi}} \mathrm{CD} 25^{-}$cells with parakeratosis $(\mathrm{p})$, acanthosis (a), dermal inflammatory infiltrates (di), basilar papilla (bp), and epidermal microabscess (em) as indicated. Original magnification, $\times 400$. (D) Intracellular cytokine staining was performed on pooled cervical lymph node cells collected from mice that received CD4+CD45RB hi CD25- T cells. Results shown are gated on CD4+ population. (E) Quantitative RT-PCR for the cytokines was performed on ear mRNA, with results reported as group means $\pm \operatorname{SEM}(n=10)$. Data are representative of at least 2 independent experiments. 
A
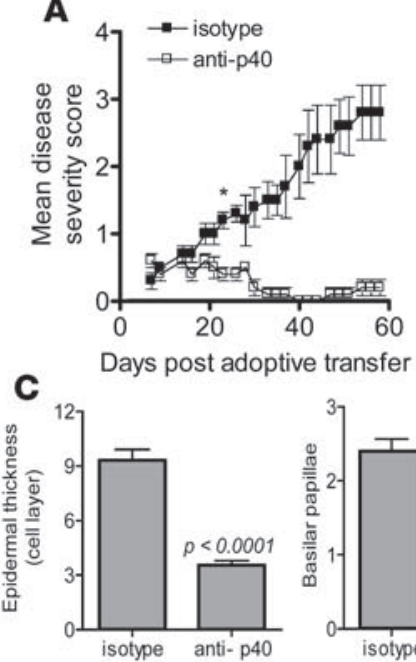

D
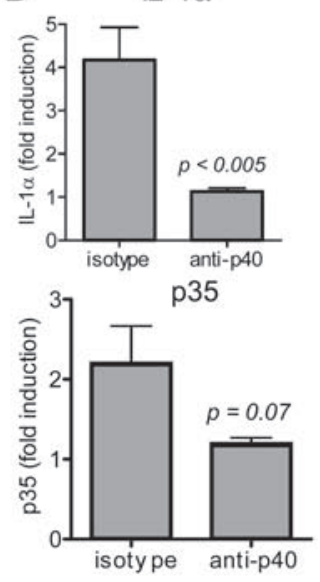

p19

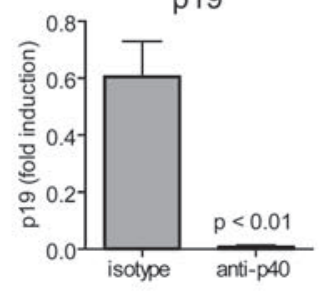

B

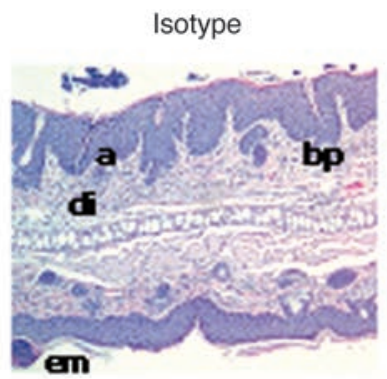

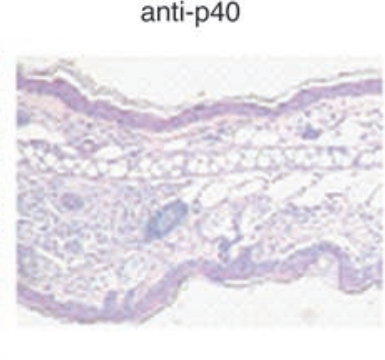

anti-p40

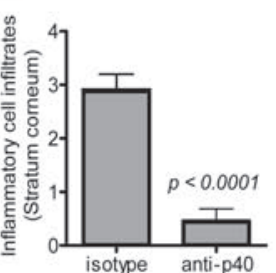

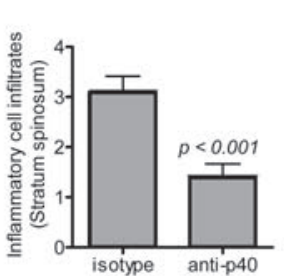

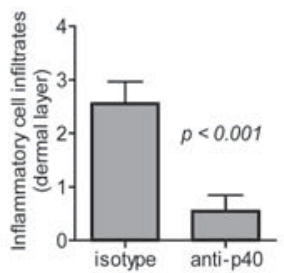

IL-6
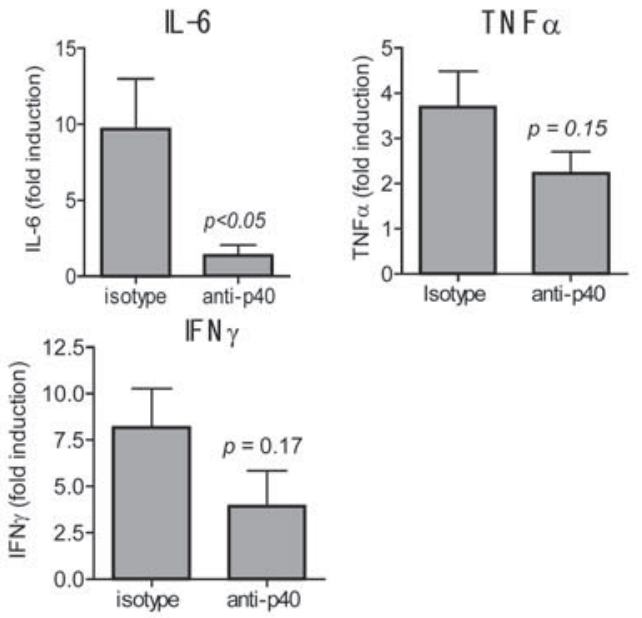

IL $-17 \mathrm{~A}$
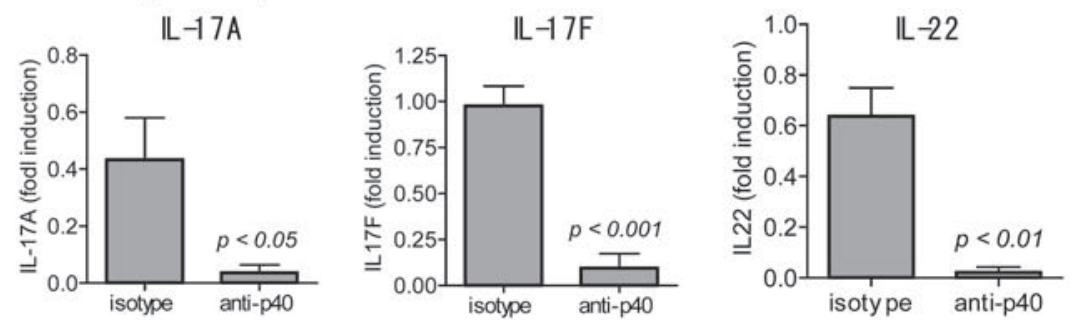

Figure 3

IL-12/IL-23p40 neutralization prevents the development of skin lesions. (A) Disease severity in CB17 scid/scid mice receiving first CD4+CD45RB hiCD25- cells and subsequently treated with either $0.5 \mathrm{mg}$ of IL-12/23p40 antibody or isotype control antibody (rat lgG2a) i.p. on days 7 and 35 after the adoptive transfer. The mean disease severity scores are reported for 10 mice from each group $\pm S E M{ }^{*} P<0.05$ starting on day 24, comparing the 2 groups. Data are representative of at least 2 independent experiments. (B) Representative images of H\&E-stained sections of ear from recipient CB17 scid/scid mice given an isotype control antibody (left) or IL-12/23p40 antibody (right). Examination of the sections indicates the presence of acanthosis (a), dermal inflammatory infiltrates (di), prominent basilar papilla (bp), and epidermal microabscesses $(\mathrm{em})$ in isotype control antibody-treated mouse skin. Original magnification, $\times 200$. (C) Epidermal thickness and semiquantitative scoring of basilar papillae and inflammatory infiltrates in the stratum corneum, stratum spinosum, and dermal layer of the skin. A section from each mouse ear was scored as follows: 0 , within normal limits; 1 , minimal; 2 , mild; 3 , moderate; 4 , marked; and 5 , severe. The means \pm SEM are shown, with $n=10$ for each group. (D) Quantitative RT-PCR analysis for each indicated cytokine in RNA isolated from mouse ear at the end of the study. Results reported as mean \pm SEM. Data are representative of at least 2 independent experiments, with $n=10$ for each group.

Although morphologic and immunologic differences exist between this model and human psoriasis, microscopic evaluation of lesional skin samples revealed histologic characteristics typically associated with psoriasis, including hyperkerato- sis, keratinocyte hyperplasia with acanthosis, basilar papillae, and intense inflammatory cell infiltrates consisting mainly of mononuclear cells, as shown for ear and back skin in Figure 2C. Also observed was the formation of epidermal microabscesses 
A

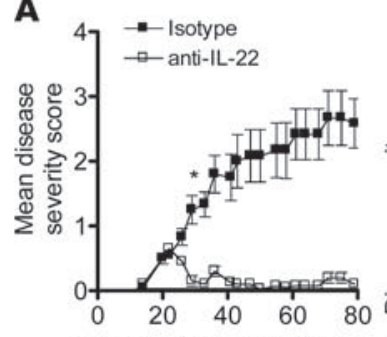

C

Isotype

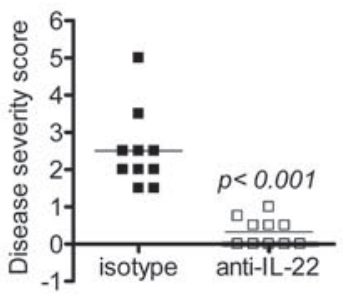

anti-IL-22
B

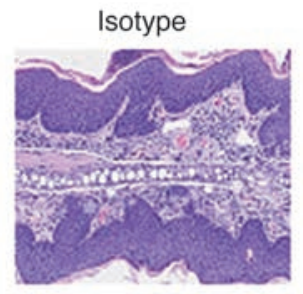

anti-IL-22

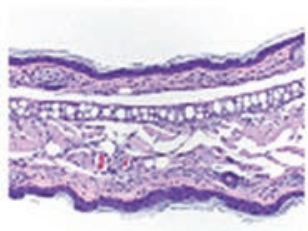

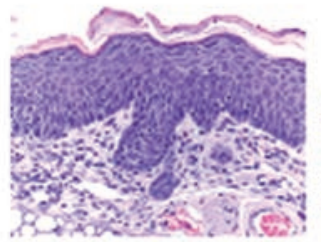

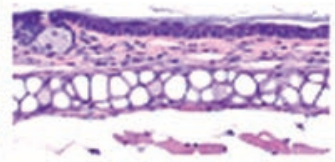

D

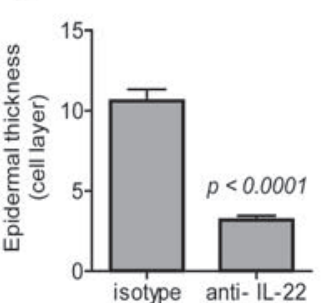

E
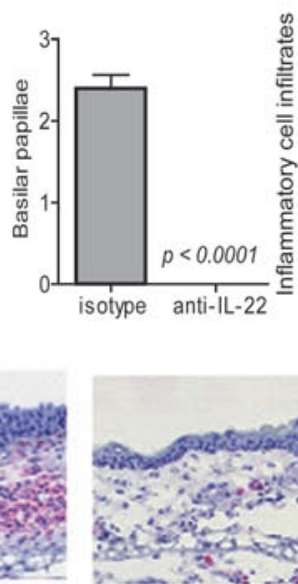

G

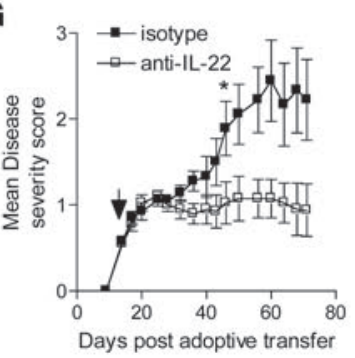

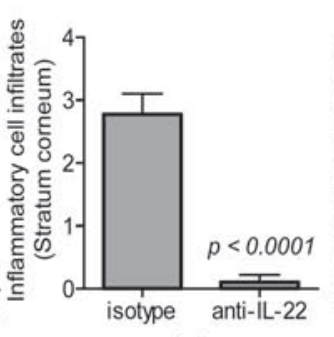
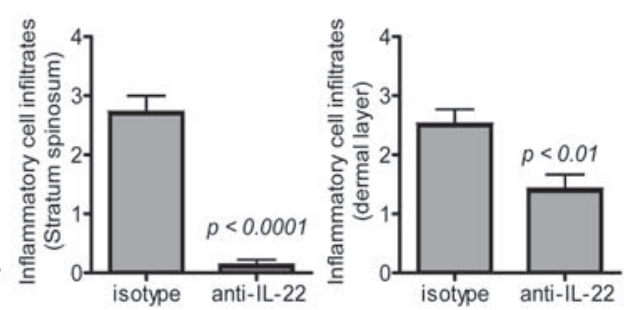

F $\quad \mathrm{CD} 4$
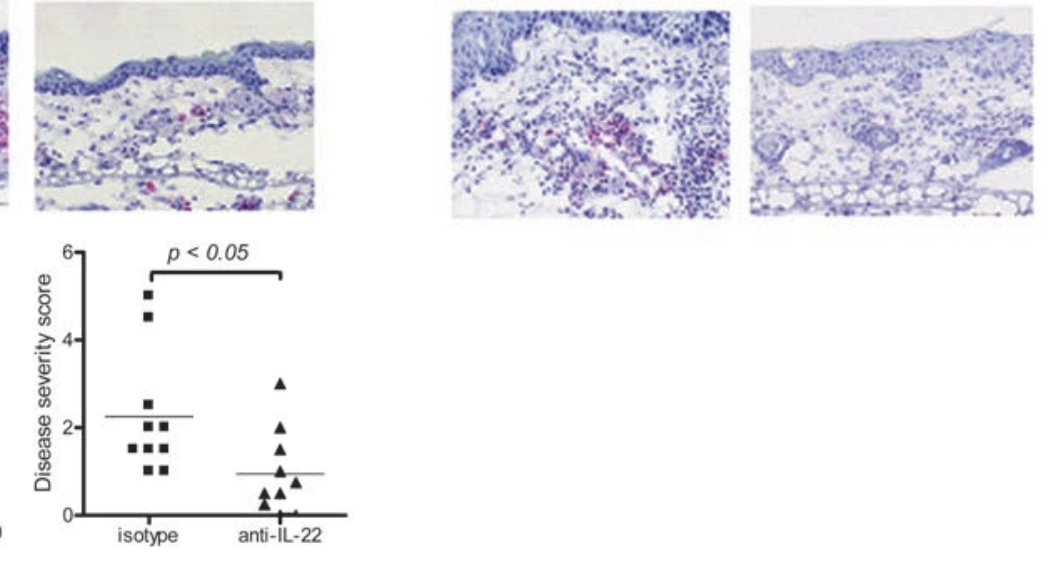

\section{Figure 4}

IL-22 neutralization prevents the development of skin lesions. (A) Left panel shows the mean disease severity $( \pm$ SEM) in recipient mice that were given $16 \mathrm{mg} / \mathrm{kg}$ of IL-22 (IL22-104) or isotype control antibody, i.p. once per week for 11 weeks. ${ }^{*} P<0.05$ starting on day 26, comparing the 2 groups, with $n=10$ mice. Right panel shows the disease severity scores at the end of the study. Data are representative of at least 2 independent experiments. (B and C) H\&E-stained sections of ear tissue from recipients given an isotype control (left) or IL-22 antibody (right). Original magnification, $\times 200$ (B) and $\times 400$ (C). (D) Epidermal thickness and semiquantitative scoring of basilar papillae and inflammatory infiltrates in the indicated skin layers. A section from each mouse ear was scored as follows: 0 , within normal limits; 1 , minimal; 2 , mild; 3 , moderate; 4 , marked; and 5 , severe. Means \pm SEM are shown, with $n=10$ mice. (E and $\mathbf{F})$ Representative immunohistochemical staining for $C D 11 \mathrm{~b}^{+}(\mathbf{E})$ and $C D 4^{+}(\mathbf{F})$ in ear sections from recipients given isotype control antibody (left) or IL-22 antibody (right). Original magnification, $\times 400$. (G) Mean disease severity in recipient mice after cell transfer and subsequent weekly treatment starting on day 14 with $16 \mathrm{mg} / \mathrm{kg}$ of IL-22 (IL22-103) or isotype control antibody (as indicated by arrow). ${ }^{*} P<0.05$ on day 46 comparing the 2 groups $(n=10$ mice). Right panel shows individual disease severity scores at the end of the study.

(Figure 2C). Altogether, these observations demonstrate that elimination of Tregs from the $\mathrm{CD} 4^{+} \mathrm{CD} 45 \mathrm{RB}^{\text {hi }}$ populations leads to the development of a more extensive disease with psoriasis-like pathology.
To determine the type of $\mathrm{T}$ cell response in our model, we examined the cytokine profile of $\mathrm{T}$ cells in the cervical lymph nodes, as the majority of the mice developed lesions around the face and neck. As shown in Figure 2D, CD4+ $\mathrm{T}$ cells from mice transferred 
A

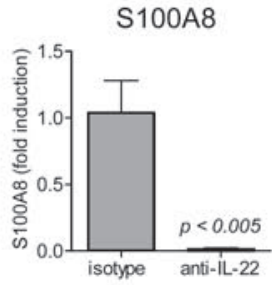

B
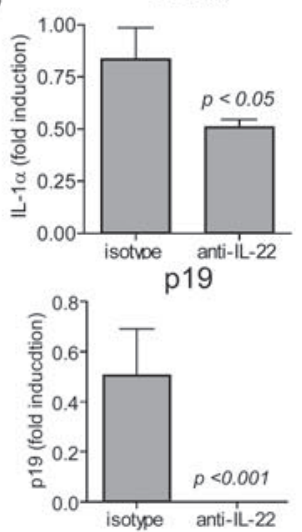

S100A9

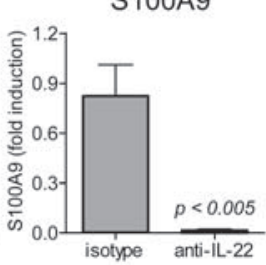

$\mathbb{L L}-1 \beta$

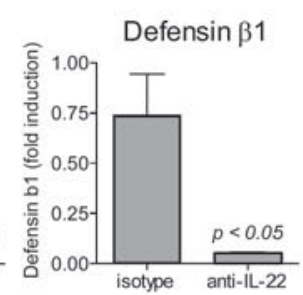

IL-6

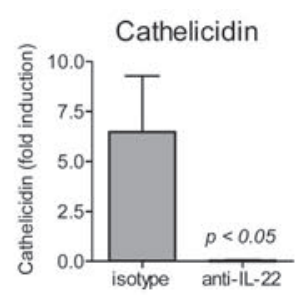

TNF $\alpha$ p35
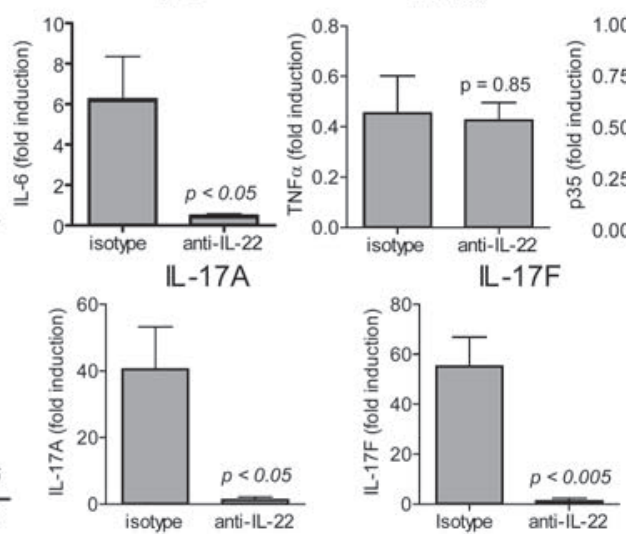

IL-22

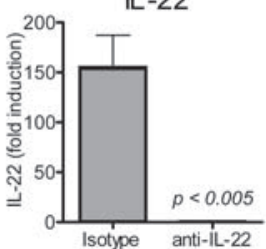

anti-IL-22
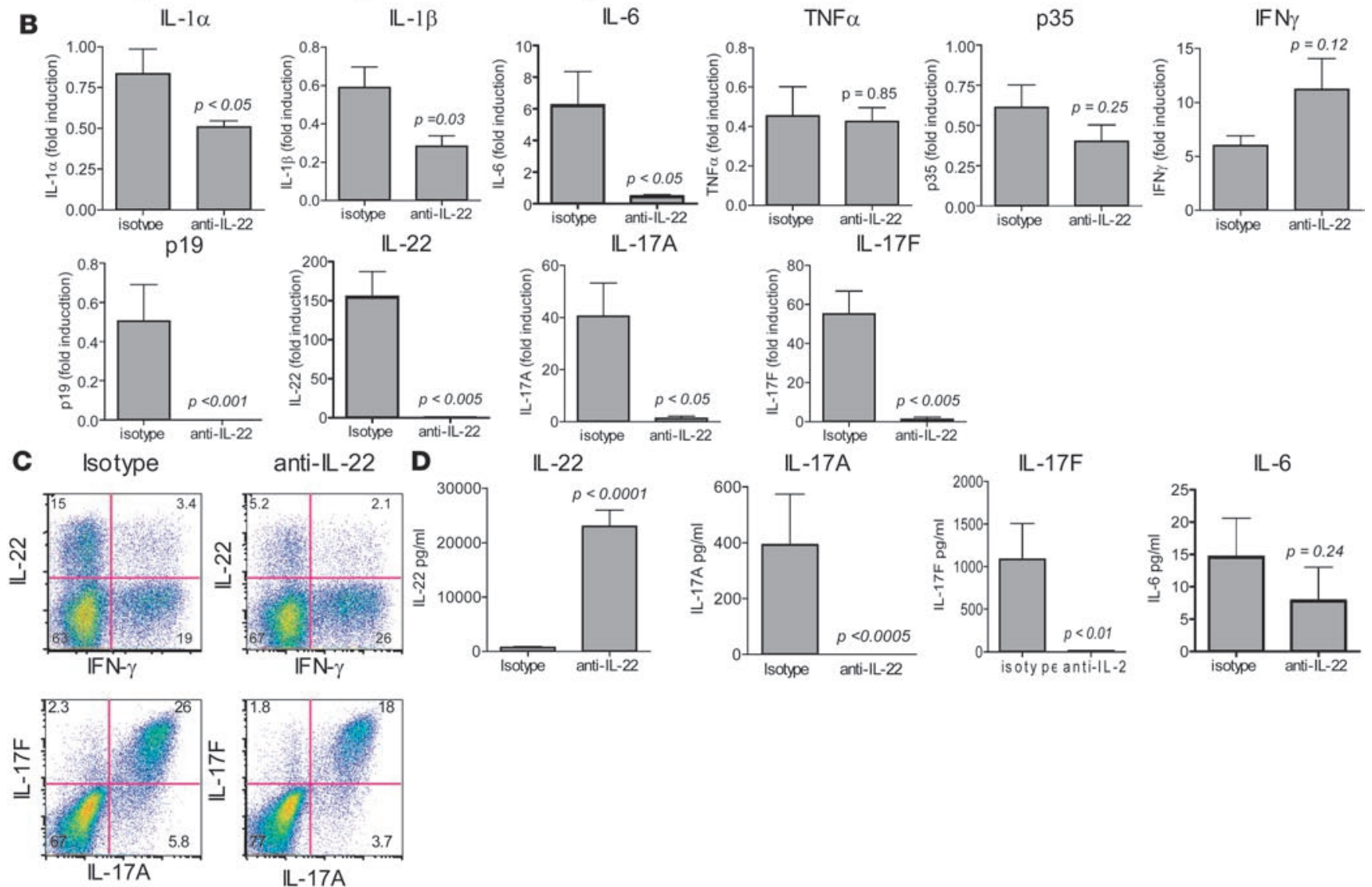

\section{Figure 5}

IL-22 neutralization influences gene expression, T cell phenotype, and cytokine profile. Recipient mice received an i.p. injection of IL-22 antibody (IL22-104) or isotype control antibody immediately before adoptive transfer and weekly thereafter. At the termination of the study, quantitative RT-PCR was performed on the RNA isolated from individual mouse ears for transcripts encoding (A) antimicrobial peptides and (B) cytokines. Results are reported as means \pm SEM. All data are representative of at least 2 independent experiments, with $n=10$ for each group. (C) Intracellular cytokine staining for IL-22, IL-17A, IL-17F, and IFN- $\gamma$ performed on pooled cervical lymph node cells collected from mice treated with isotype control or IL-22 antibody. Results shown are gated on the CD4+ population. Data are representative of at least 2 independent experiments. (D) Serum was collected at the termination of a study from mice given isotype or IL-22 antibody. Serum IL-22, IL-17A, IL-17F, and IL-6 were determined by standard ELISA. Results are reported as group means \pm SEM, with $n=10$ for each group. TNF- $\alpha$ and IFN- $\gamma$ were below the limit of detection of this assay. Data are representative of at least 2 independent experiments.

with CD4+CD45RB hiCD25- cells expressed IFN- $\gamma(17 \%)$ or IL-17A $(32 \%)$, indicating that Th1 and Th17 cells were present in this model. We did not detect IL-4-expressing T cells (data not shown). We also detected IL-22 in $21 \%$ of the $\mathrm{CD}^{+} \mathrm{T}$ cells, and most of these (86\%) also coexpressed IL-17A.

To determine whether these cytokines were expressed in lesional skin, quantitative RT-PCR was performed on mRNA from mouse ear biopsies. Compared with mRNA from naive mice, diseased recipient mice showed a significant increase in proinflammatory cytokine transcripts encoding IL-1 $\beta$, IL- 6 , TNF- $\alpha$, and IFN- $\gamma$, indicative of Th1 cells, as well as IL-17A, IL-17F, and IL-22 transcripts, indicative of Th17 cells (Figure 2E). IL-4 and IL-13 expression was not detected by quantitative RT-PCR (data not shown), indicating that Th2 cells were not present at the site of disease. These results demonstrate that transfer of naive $\mathrm{CD} 4^{+} \mathrm{T}$ cells into the recipient mice led to the development of Th1 and Th17 effector cells that might drive disease progression. Cytokines made by these $\mathrm{T}$ cell lineages are also upregulated in human psoriasis lesions (20-23).

IL-12/23p40 neutralization reduces Th17 cytokine expression and prevents disease development. IL-12 and IL-23 are produced by macrophages and DCs, which play pivotal roles in driving Th1 and Th17 responses, respectively. As significant increases in Th1 and Th17 
A
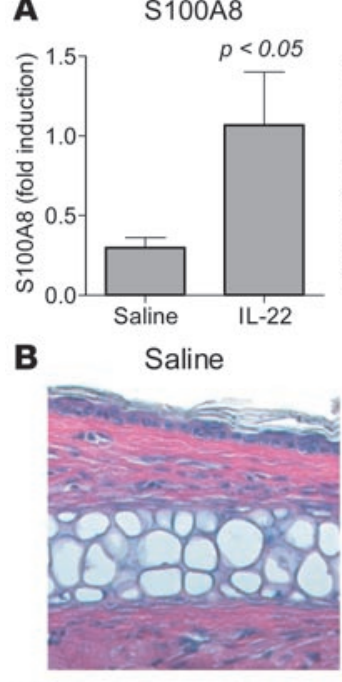

C

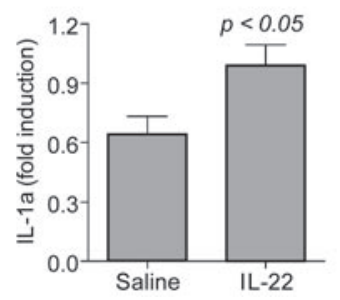

S100A9

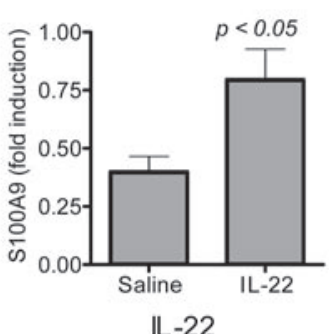

IL-22

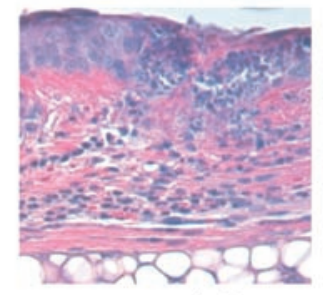

IL-6

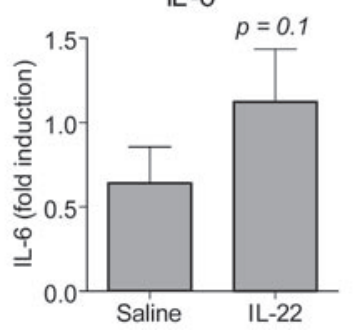

Defensin $\beta 1$
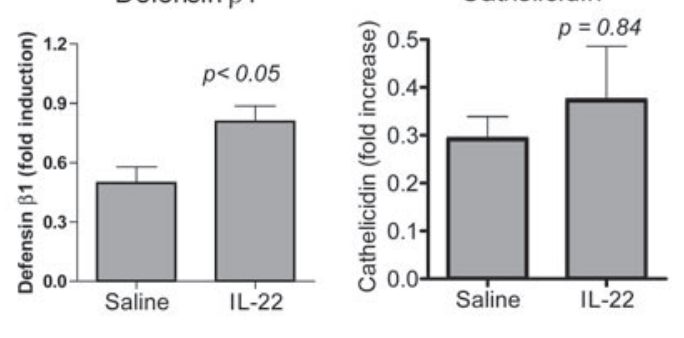

Figure 6

IL-22 induces antimicrobial peptide and proinflammatory cytokine gene expression and keratinocyte hyperplasia in the skin. Ears of BALB/C mice were injected intradermally every other day for 2 weeks with $500 \mathrm{ng}$ of IL-22 or saline in a total volume of $20 \mu \mathrm{l}$. (A) 6 hours after the first injection, mouse ears were harvested, RNA purified, and antimicrobial peptide transcript levels evaluated by quantitative RT-PCR. Results are reported as group means \pm SEM, with $n=5$ for each group. (B) H\&E-stained sections 2 weeks after injection from ears injected with saline (left panel) or IL-22 (right panel). Note the keratinocyte proliferation and inflammatory infiltrates. Original magnification, $\times 400$. (C) After 2 weeks of injections, mouse ears were harvested, RNA purified, and cytokine transcript levels evaluated by quantitative RT-PCR. Results are reported as group means \pm SEM, with $n=5$ for each group. Data are representative of at least 2 independent experiments.

cytokine expression were found in our model, we next determined whether blocking the IL-12 and IL-23 pathways would alleviate disease progression. Mice were administered a neutralizing antibody that binds to the $\mathrm{p} 40$ subunit of IL-12 and IL-23 or an isotype control antibody. As demonstrated in Figure 3A, mice treated with the IL-12/23p40 antibody did not develop disease, whereas control mice developed severe psoriaform lesions with a mean disease severity score of $2.7 \pm 0.4$ at the end of the study. Skin from control mice had a markedly thickened epidermal layer and increased numbers of basilar papillae when compared with mice treated with the IL-12/23p40 antibody (Figure 3B). The lack of gross skin lesions in mice treated with the IL-12/23p40 antibody also correlated with a dramatic decrease in inflammatory infiltrates in the stratum corneum, stratum spinosum, and dermal layers (Figure 3C). IL-12/23p40 pathway blockade almost completely abrogated acanthosis, parakeratosis, and inflammatory cell infiltrates in the skin biopsies.

To examine the effect of IL-12/23p40 neutralization on cytokine responses, we performed quantitative RT-PCR on the mRNA from mouse ears of each group. IL-12/23p40 antibody treatment significantly decreased IL- $1 \alpha$ and IL- 6 transcripts, whereas TNF- $\alpha$ expression was reduced but not significantly. There was about a $50 \%$ reduction in IL-12p35 and IFN- $\gamma$ transcripts, which did not reach statistical significance, suggesting that Th1 cells were still present in the tissue in the presence of IL-12/23p40 antibody. In contrast, IL-23p19, IL-17A, IL-17F, and IL-22 transcript levels were reduced in the IL-12/23p40 antibody-treated mice by approximately 10 -fold each (Figure 3D). Of note, we detected similar amounts of the abovementioned transcripts in untreated (mice with $\mathrm{T}$ cell transfer that were not treated with antibody) and isotype control-treated mice (data not shown). These data indicate a better correlation of disease phenotype with Th17 cytokines than with Th1 cytokines. Taken together, these results suggest that Th17 cells are the major effectors that drive disease progression in this psoriasis-like model.

IL-22 neutralization reduces cellular infiltrates and prevents disease development. Previous data demonstrated that transfer of $\mathrm{CD} 4{ }^{+} \mathrm{CD} 45 \mathrm{RB}^{\text {hi }} \mathrm{T}$ cells from IFN- $\gamma^{-/-}$donors led to slightly reduced disease severity, suggesting that skin inflammation could be mediated by an alternative pathway (7). The fact that IL-12/23p40 antibody was effective in blocking disease development in our model suggested the involvement of Th17 cells in this alternative pathway. Th17 cells produce both IL-17 and IL-22 cytokines (13), and IL-22 is able to effect keratinocyte hyperplasia and acanthosis in both mouse and human skin $(9,23)$. To determine whether IL-22 is involved in disease progression in our model, we treated mice with an IL-22-neutralizing or isotype control antibody immediately before the adoptive transfer of $\mathrm{CD} 4{ }^{+} \mathrm{CD} 45 \mathrm{RB}{ }^{\text {hi }} \mathrm{CD} 25^{-}$cells 
and once per week thereafter. The control antibody treated-mice developed acanthosis and scaly skin that subsequently appeared on the rest of the body. The average disease severity score at the end of the study shown in Figure 4A was $2.6 \pm 0.4$. Mice treated with IL-22 antibody developed only erythema of the ears and eyelids that resolved as early as 26 days after the adoptive transfer (Figure 4A). Mice in the treatment group had an average disease severity score of $0.2 \pm 0.08$ at the end of the study. Histopathological analysis showed that control mice had hyperkeratosis, epidermal microabscesses, acanthosis, prominent basilar papilla, and dilated blood vessels, whereas mice treated with the IL-22 antibody had either normal skin or mild histopathological findings (Figure 4, B and C). Furthermore, control antibody-treated mouse skin had a markedly thickened epidermal layer (Figure 4D) and an increased number of basilar papillae (Figure 4D), the latter reminiscent of rete pegs in human psoriasis. These features of skin pathology were completely absent in mice treated with IL-22 antibody. The decrease in skin pathology correlated with a decrease in infiltrating inflammatory cells in the stratum corneum, stratum spinosum, and dermal layer (Figure 4D). In particular, we found

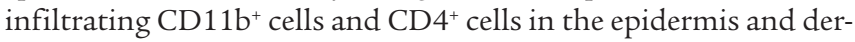
mis (Figure 4, E and F, and data not shown). The number of these cells was reduced or completely absent in the IL-22 antibody-treated group as were neutrophils in the microabscesses of the epidermis (data not shown). A distinct IL-22 antibody was efficacious in a more therapeutic setting where mice started receiving IL-22 antibody 2 weeks after cell transfer, when all recipient mice presented with skin inflammation around the ears and the eyes. Compared with the isotype control antibody group, mice treated with this IL-22 antibody maintained significantly lower disease scores starting on day 46 after the $T$ cell transfer or 32 days after administration of IL-22 antibody (see Figure 4G and Supplemental Figure 3 for use of this IL-22 antibody in prophylactic regimen). Collectively, these results demonstrated that IL-22 neutralization was effective in blocking the development of psoriasis-like skin inflammation in this CD4 T cell-dependent model.

IL-22 neutralization influences gene expression, T cell phenotype, and serum cytokine profile. Immune cells do not express the IL-22 receptor complex; therefore, the protective effect of IL-22 blockade observed in our model was presumably not mediated through direct neutralization of IL-22 signaling in the immune cell compartment. Since the IL-22 receptor is present on the surface of keratinocytes $(14,23)$, we evaluated the effect of IL-22 neutralization on gene expression in the skin. Quantitative RT-PCR analysis of mouse ear mRNA demonstrated that IL-22 antagonism led to a significant reduction in several antimicrobial peptide transcripts including S100A8 (calgranulin A), S100A9 (calgranulin B), defensin $\beta 1$, and cathelicidins (Figure $5 A)$. Additionally, transcript levels for IL- $1 \alpha / \beta$, IL-6, IL-23p19, IL-22, IL-17A, and IL-17F were significantly reduced in the IL-22 antibody-treated mice. TNF- $\alpha$ and IL-12p35 expression were relatively unchanged whereas IFN- $\gamma$ was elevated 2 -fold (not significant) when compared with the control mice (Figure 5B). Of note, we detected similar amounts of the above-mentioned gene transcripts in untreated (mice with adoptive transfer of T cells but not treated with antibody) and isotype control antibody-treated mice (data not shown). These results indicate that IL-22 neutralization prevented the expression of genes for antimicrobial peptides, inflammatory cytokines, and Th17 cytokines. To determine the influence of IL-22 blockade on the $\mathrm{CD}^{+}$cell population, we performed intracellular cytokine staining on cells from pooled draining cervical lymph nodes obtained at the end of the study. Compared with mice treated with isotype antibody, mice treated with the IL-22 antibody had an approximately 2 -fold reduction in IL-22-expressing cells, from $18.4 \%$ to $7.3 \%$, accompanied by a slight increase in IFN- $\gamma$-expressing cells, from $22.4 \%$ to $28.1 \%$ (Figure $5 \mathrm{C}$ ). Fewer $\mathrm{CD}^{+}{ }^{+} \mathrm{T}$ cells from the IL-22 antibody-treated mice were positive for IL-17A (21.7\%) and IL-17F (19.8\%) compared with isotype control-treated mice $31.8 \%$ and $28.3 \%$, respectively) (Figure 5C). Collectively, these results demonstrate that IL-22 blockade results in decreased numbers of Th17 cells in the affected skin and draining lymph nodes. We also determined the effect of IL-22 neutralization on the serum levels of cytokines at the end of the study. Mice in the isotype control antibody group, which developed disease, had detectable circulating levels of IL-17A (average $=400 \mathrm{pg} / \mathrm{ml})$ and IL-17F (average $=1,000 \mathrm{pg} / \mathrm{ml}$ ), which were significantly reduced with IL-22 antibody treatment. IL- 6 was detected in the control mice (average $=15 \mathrm{pg} / \mathrm{ml}$ ) but not significantly reduced with IL-22 antagonism. IFN- $\gamma$ and TNF- $\alpha$ levels in both groups were below the limit of detection $(<2 \mathrm{pg} / \mathrm{ml}$ and $<6 \mathrm{pg} / \mathrm{ml}$, respectively). IL-22 antibody-treated mice, on the other hand, exhibited higher IL-22 levels (average $=24,000 \mathrm{pg} / \mathrm{ml}$ ) than control antibody treated-mice. As the ELISA used for the detection of IL-22 can detect IL-22 complexed with the neutralization antibody, this elevated detection of IL-22 suggests that IL-22 antibody captured and stabilized biologically inactive IL-22. A similar elevation of serum TNF- $\alpha$ has been described in humans with rheumatoid arthritis that were treated with a TNF- $\alpha$ inhibitor (infliximab) (24). Overall, these results show that IL-22 neutralization profoundly reduced Th17 cytokine serum protein and skin transcript levels and altered the balance of Th1 and Th17 subsets in the draining lymph nodes. These data further suggest that the function of IL-22 is central to the mechanisms that sustain the development of psoriasis-like skin inflammation in this $\mathrm{CD}^{+} \mathrm{T}$ cell-dependent model.

IL-22 induces antimicrobial peptide and proinflammatory cytokine gene expression in mouse skin. As IL-22 neutralization prevented antimicrobial peptide and inflammatory cytokine gene expression in our model, we asked whether IL-22 itself could induce the expression of these genes directly in mouse skin. IL-22 or saline was injected into wild-type BALB/c mouse ears every other day for 2 weeks. RNA from mouse ears was prepared for quantitative RT-PCR analysis 6 hours and 2 weeks after the first injection. As demonstrated in Figure 6A, IL-22 but not saline induced a significant increase in S100A8, S100A9, and defensin $\beta 1$ but no increase in cathelicidin transcripts 6 hours after the initial injection. IL- $1 \alpha$, IL-6, and TNF- $\alpha$ transcripts and histopathologic changes were undetectable after 6 hours (data not shown). At the end of the 2 weeks, we found that IL-22 but not saline induced keratinocyte hyperplasia in mouse ears (Figure 6B) as well as increased defensin $\beta 1$, S100A8, and S100A9 transcripts (data not shown). IL-22 also significantly induced IL-1 $\alpha$ gene expression, with a trend toward increased IL-6 and TNF- $\alpha$ transcripts (Figure 6C). Neither Th1 nor Th17 cytokine transcripts were detected after 2 weeks of IL-22 treatment. These results suggest that IL-22 can directly induce antimicrobial peptide and proinflammatory cytokine production from the skin that can drive the expansion of an autoreactive $T$ cell compartment if available.

\section{Discussion}

We report a mouse model of psoriasis-like disease using adoptive transfer of naive $\mathrm{CD} 4{ }^{+} \mathrm{CD} 45 \mathrm{RB}^{\text {hi }} \mathrm{T}$ cells depleted of $\mathrm{CD} 25^{+}$Tregs into scid/scid mice. Recipient mice develop skin lesions but rarely 
colitis when housed under sterile and static conditions. Macroscopically, the affected mice develop scaly and raised skin plaques. Microscopically, they develop skin abnormalities that resemble aspects of human psoriasis, including hyperkeratosis, acanthosis, and inflammatory cell infiltrates of CD $11 \mathrm{~b}^{+}$cells, $\mathrm{CD} 4^{+}$cells, and neutrophils in the epidermis and dermis. Collectively, our observations in this model indicate similarities to human psoriasis.

There are also dissimilarities between our model and human psoriasis. Unlike human psoriasis, in which $\mathrm{CD}^{+}$cells are implicated in disease pathology $(25,26), \mathrm{CD}^{+}$lymphocytes appear to be solely responsible for the induction of disease in our model. Additionally, mouse skin is not thought to form true rete pegs observed in psoriasis because of the short interfollicular regions $(4,27)$. The observed basilar papilla could be due to follicular hyperplasia that results in hair loss and that rarely occurs in psoriasis patients. We found that basilar papilla in our serially sectioned skin tissues rarely coincided with hair follicles (data not shown). While there are some distinctions, the cytokine gene expression profile of affected tissue mirrored that present in lesions of human psoriasis, with upregulation of IL-6, IL-17A, IL-17F, IL-22, IFN- $\gamma$, and TNF- $\alpha$.

Skin disease incidence and severity were greatly increased by removing $\mathrm{CD} 4{ }^{+} \mathrm{CD} 25^{+}$Tregs from the adoptive transfer cell preparation. Tregs from psoriasis patients have reduced immunosuppressive activity ex vivo. Depletion of Tregs has been linked to the hyperproliferation of $\mathrm{T}$ cells and the development of autoimmunity in animal models $(18,28)$. A fine balance of effector $\mathrm{T}$ cells and Tregs regulates immune and autoimmune responses. TGF- $\beta$ produced by naturally occurring Tregs and other cell types promotes the development of Tregs that participate in immune regulation (29). In contrast, a combination of IL- 1 and IL- 6 with TGF- $\beta$ promotes the differentiation of Th17 cells (13), which are potent inducers of autoimmunity (30). A lack of naturally occurring Tregs in our mouse model plus the induction of proinflammatory cytokines like IL-1, IL-6, and TNF- $\alpha$ in the diseased skin may tip the balance of immune homeostasis by favoring the development of Th17 cells that enhance cutaneous inflammation.

We demonstrate that Th17 cells have a major role in our psoriasis-like disease model. The IL-12/23p40 antibody used here and in the previously described model (7) blocks both IL-12 and IL-23 signaling that is crucial for the differentiation or maintenance of Th1 and Th17 T cells, respectively. With the identification of the Th17 lineage subsequent to the report of Hong et al., we now report elevated levels of both Th17 cytokine (IL-17A, IL-17F, and IL-22) and Th1 (IFN- $\gamma$ ) transcripts in the affected skin of scid/scid recipient mice transferred with $\mathrm{CD} 4{ }^{+} \mathrm{CD} 45 \mathrm{RB}{ }^{\text {hi }}$ cells, either in the presence or absence of IL-12 and LPS. Adoptive transfer of IFN- $\gamma$ deficient $\mathrm{T}$ cells induced disease in recipient mice, albeit with delayed onset and severity, suggesting that cells other than Th1 may be involved in the disease process (7). The significant suppression of IL-23p19, IL-17A, IL-17F, and IL-22 transcripts with the IL-12/23p40 antibody treatment suggests that an alternative pathway that also leads to disease progression may be attributed to Th17 cells. Our data are also in agreement with the recent observation that intradermal injection of IL-23 induces more severe psoriaform lesions than IL-12 in mice (9). Inhibiting the IL-22 pathway but not the IL-17A pathway prevented the progression of cutaneous inflammation induced by IL-23 intradermal injection, suggesting that IL-22 is a key player in the induction of skin inflammation downstream of IL-23 $(8,9)$.
The incomplete downregulation of Th1 transcripts in the presence of disease resolution in our model suggests either that Th1 cells do not play a major role in the disease pathology or, alternatively, that maintaining a certain IFN- $\gamma$ level is critical during the recovery phase of the disease. Several autoimmune disease models including lupus nephritis, EAE, and rat insulin-induced diabetes have implicated a beneficial role for IFN- $\gamma$ in limiting disease progression $(31,32)$. Further evaluation of cytokine gene expression during the disease induction and maintenance phases may help in dissecting the roles of various cytokines at different time points of disease development.

Multiple cytokine genes, including IL-6, IL-17A, IL-17F, IL-21, IL-22, IL-23, and TNF- $\alpha$, are significantly upregulated in human psoriaform lesional skin compared with nonlesional skin (16, 22). Therapeutic antibodies that bind to IL-12/23p40 and result in the neutralization of IL-12 and IL-23 activity have been used successfully to treat psoriasis (33-35). In our hands, IL-12/23p40 antibody treatment was also efficacious in reducing skin inflammation. Cytokine gene expression revealed that blocking the IL-12 and IL-23 pathways with IL-12/23p40 antibody significantly downmodulated IL-1 $\alpha$, IL-6, IL-17A, IL-17F, IL-22, and IL-23 and tended toward decreasing IL-12, IFN- $\gamma$, and TNF- $\alpha$ expression. Among these genes, IL-6, IL-17A, IL-22, IFN- $\gamma$, and TNF- $\alpha$ were also suppressed in a human clinical trial evaluating the efficacy of an IL-12/23p40 antibody in psoriasis $(34,36)$. These similarities suggest that the immune mechanisms involved in this mouse model are similar to those involved in human psoriasis. Our results build on the previous study by Hong et al. (7) and further emphasize the complexity of the signaling mechanisms, cytokine network, and cellular interactions in this mouse skin inflammation model.

We show that blockade of IL-22 activity prevents the progression of skin inflammation in an animal model that shares features with human psoriasis. Our data also indicate that IL-22 antagonism leads to a reduction in the Th17 compartment in the cervical lymph nodes and decreased tissue expression of cytokines produced by these cells. Besides $\mathrm{CD} 4^{+} \mathrm{T}$ cells, we also detected a reduced number of NK cells in the draining lymph nodes presumably generated from the host (data not shown). As NK cells are capable of inducing IFN- $\gamma$, IL-17, and IL-22 gene expression $(14,23,37)$, our results may indicate a role for NK cells in this model of disease progression.

IL-22 is unable to exert a direct effect on Th17 cells, as immune cells do not express the IL-22 receptor. Instead, IL-22 most likely modulates the immune response indirectly through its effects on keratinocytes, which express both chains of the IL-22 receptor (14, 16). IL-22 mediates keratinocyte activation via phosphorylation of the Stat 3 transcription factor. Upregulation of Stat 3 is associated with keratinocyte hyperproliferation and psoriasis, and constitutive expression of active Stat 3 in keratinocytes leads to spontaneous psoriaform lesions in a Stat3 transgenic model (38). Thus, activation of the IL-22 pathway probably effects keratinocyte activation via STAT3 signaling in our model, ultimately resulting in the enhanced epidermal thickness that we observe.

Our data suggest that keratinocytes, nonimmune tissue cells, contribute to the amplification and maintenance of inflammatory responses by responding to the IL-22 produced by infiltrating Th17 effector lymphocytes. Our data also suggest that IL-22 contributes to the maintenance of Th17 cells themselves, possibly by providing an appropriate local inflammatory environment for activation of autoreactive T cells. In EAE, naive autoreactive T cells 
can travel to the CNS and become activated in response to new epitopes, contributing to epitope spreading in the disease (39). Thus, in our model, the activity of IL-22 on keratinocytes may be critical for the establishment of an inflammatory environment needed for continued pathogenic priming of autoreactive T cells. IL-22 activation of human keratinocytes stimulates a variety of proinflammatory cytokines (IL-6, IL-1, IL-8, and TNF- $\alpha$ ) and antimicrobial peptides associated with host defense $(40,41)$. Here, we demonstrate that IL-22 induces IL-1, IL- 6 , and TNF- $\alpha$ gene expression in mouse skin, which may favor Th17 differentiation. Neutralization of IL-22 leads to a reduction of IL- 1 and IL- 6 gene expression in the skin and thus may prevent further Th17 differentiation. We also show that IL-22 induces antimicrobial peptide gene expression in mouse skin. Some antimicrobial peptides, including defensins and cathelicidins, have a chemotactic function that enhances cutaneous inflammation by activating and recruiting immune cells such as $\mathrm{CD}^{+}$cells, neutrophils, macrophages, and dendritic cells (40, 41). In our study, we found that IL-22 neutralization significantly reduced cutaneous expression of S100A8 (calgranulin A), S100A9 (calgranulin B), defensin $\beta 1$, and cathelicidins. These reductions may prevent further recruitment and activation of immune cells, as demonstrated by decreased numbers of infiltrating cells in the IL-22 antibody-treated group. Interestingly, blockade of the IL-22 pathway resulted in decreased Th17 but enhanced Th1 (IFN- $\gamma$ ) cells in cervical lymph nodes, suggesting that this Th17 cytokine has indirect regulatory effects on Th1 cells.

Collectively, our observations indicate an important role for Th17 effector lymphocytes and IL-22 in the pathogenesis of psoriasis-like disease in our model. IL-22 is expressed by infiltrating Th17 cells and acts directly on keratinocytes but not on immune cells, the latter of which do not express the IL-22 receptor. Our data suggest that gene products of nonimmune tissue cells downstream of IL-22 signaling contribute to the establishment of the inflammatory environment needed for the development of the psoriasis-like disease. Our model demonstrates that IL-22 activity is required for this pathogenic interplay between the keratinocytes and the immune system. Neutralization of IL-22 activity reduces the expression of inflammatory mediators by epithelial cells and keratinocytes as well as the recruitment and maintenance of inflammatory Th17 cells at the tissue site. We propose that IL-22 antagonism represents a promising therapeutic approach for the treatment of Th17-mediated inflammatory skin disorders in humans.

\section{Methods}

Mice. Female BALB/cBy (donor) and C.B-17/prkdc scid/scid (recipient) mice were purchased from The Jackson Laboratory. All mice were housed in a specific pathogen-free environment at a Wyeth animal facility and were used between 6 and 8 weeks of age. All protocols were approved by the Wyeth Animal Care and Use Committee.

Reagents. Recombinant mouse IL-12 and LPS from Salmonella enteritidis were purchased from BD Pharmingen and Sigma-Aldrich, respectively. PE-conjugated anti-CD4, FITC-conjugated anti-CD45RB, and APC-conjugated anti-CD25 were purchased from BD Pharmingen. Anti-mouse IL-12/23p40 (clone C17.8), and isotype control antibody (rat IgG2a) were purchased from BioLegend. Antibody to IL-17A (TC-118H10) was purchased from R\&D Systems. Methods described previously were used to generate rat antibodies specific for mouse IL-22: IL-22 Ab-01 and IL-22 Ab-03; mouse and human IL-22: IL-22 Ab-02; and mouse IL-17F: RK015-1 (42). IL22-104 and IL22-103, which bind to and potently neutralize both human and mouse IL-22 activities in vitro (Supplemental Figure 2 and data not shown), and isotype control antibody (human IgG1 $\lambda$ ) were generated internally. Results presented in Figure 4, A-F, and Figure 5 were generated with IL22-104. Figure 4G and Supplemental Figure 3 were generated with IL-22-103. Both of these antibodies are referred to as IL-22 antibody in the text.

Cell purification, adoptive transfer, and treatment of mice. Cells for adoptive transfer were prepared as previously described, with slight modification (7). $\mathrm{CD}^{+} \mathrm{T}$ cells were enriched from BALB/cBy splenocytes using a mouse CD4 enrichment kit (R\&D Systems). The cells were then labeled with PE-conjugated anti-CD4, FITC-conjugated anti-CD45RB, and APCconjugated anti-CD25 antibodies. Cells were subsequently sorted using a Moflo (Dako) cell sorter. CD4 ${ }^{+} \mathrm{CD} 45 \mathrm{RB}^{\text {hi }} \mathrm{CD} 25^{-}$cells were collected and were more than $95 \%$ pure. Cells were resuspended in saline, and $4 \times 10^{5}$ cells/mouse were injected i.p. into C.B-17/Prkdc scid/scid mice. Mice were dosed with LPS, cytokine, or antibody as indicated in Results and the figure legends. Mice were monitored for external signs of skin lesions twice each week. At termination of the study, mouse ear, back skin, lymph nodes, and spleen were collected for further ex vivo studies.

Macroscopic evaluation. Mice were evaluated in a blinded fashion by investigators twice per week starting 10 days after adoptive transfer. To record disease progression, semiquantitative disease severity scores from 0 to 6 were given to each mouse based on their external physical appearance: 0 , no skin or ear abnormalities; 0.5 , slight erythema on either the ears or eyelids; 1 , mild to moderate erythema on the ears or eyelids, with mild thickening of the ear ( $<2 \%$ of the body surface); 2 , moderate to severe erythema on $2 \%-10 \%$ of the body surface and mild scaling; 3 , severe erythema and scaling on $10 \%-20 \%$ of the body surface; 4 , very severe and extensive erythema and scaling on $20 \%-40 \%$ of the body surface; 5 , very severe and extensive erythema and scaling on $40 \%-60 \%$ of the body surface; 6 , very severe and extensive erythema and scaling on greater than $60 \%$ of the body surface. Specific observations were noted based on fur condition, ear manifestations, eyelid appearance, and presence of abnormalities on the limbs and tail.

Histopathological analysis. Tissues were processed into paraffin tissue blocks using routine methods and sectioned or serially sectioned to obtain consecutive levels. The sections were stained with H\&E. For immunohistochemistry, tissues were frozen in Optimal Cutting Temperature medium and sectioned on a cryostat, and frozen sections were stained with antibodies specific for $\mathrm{CD}^{+}$cells, $\mathrm{CD} 11 \mathrm{~b}^{+}$cells, and neutrophils. Staining was completed by incubating replicate sections in dilutions of a primary antibody to $\mathrm{CD} 4, \mathrm{CD} 11 \mathrm{~b}$ (BD Pharmingen), or neutrophils (Abcam), followed by incubation in a dilution of a secondary anti-rat biotinylated IgG antibody (H\&L; Vector Laboratories). Binding of the secondary antibody was detected in these sections using a streptavidin-labeled alkaline phosphatase (Biocare Medical) and Vulcan Fast Red (Biocare Medical) as chromogen. Histopathological evaluation of the severity of findings was performed in a blinded fashion by a board-certified veterinary pathologist using a semiquantitative scale, as indicated in the figure legends.

Cytokine detection. Serum IL-6, IFN- $\gamma$, and TNF- $\alpha$ levels were determined using corresponding ELISA kits (R\&D Systems). Antibody pairs IL-22 Ab-01 and biotinylated IL-22 Ab-03; IL-17A MAB721 and IL-17A BAF421 (R\&D Systems); IL-17F mAb 16-17 and IL-17F 15-1 were used to detect IL-22, IL-17A, and IL-17F, respectively, by sandwich ELISA.

Quantitation of cytokine transcripts. RNA was isolated from mouse ear biopsies using the QIAGEN RNeasy kit (QIAGEN). Quantitative RT-PCR for cytokine transcripts was performed using prequalified primers and probes to IL-1 $\alpha$, IL-1 $\beta$, TNF- $\alpha$, IL-22, IL-17A, IL-17F, IL-6, IFN- $\gamma$, S100A8, S100A9, defensin $\beta 1$, and cathelicidin (Applied Biosystems). The $\Delta \delta C t$ method was used to normalize transcripts to GAPDH and to calculate fold induction relative to levels detected in control mice. 
Intracellular cytokine staining. Intracellular cytokine staining was performed on cervical lymph node cells. Cells were restimulated with $50 \mathrm{ng} / \mathrm{ml}$ PMA (Sigma-Aldrich), $1 \mathrm{mg} / \mathrm{ml}$ ionomycin (Sigma-Aldrich), and GolgiPlug (Pharmingen) for 12 hours. Cells were first stained for CD4 surface antigen and then treated with Cytofix/Cytoperm (Pharmingen) according to the manufacturer's instructions. Intracellular cytokine staining was performed using antibodies to IFN- $\gamma$, IL-22, IL-17A, IL-17F, and irrelevant IgG isotype controls. IL-22 Ab-02 antibody was labeled with Alexa Fluor 647 (Molecular Probes), and IL-17F RK015 antibody was labeled with FITC (Pierce Biotechnologies), both according to the manufacturers' instructions. All plots were gated on $\mathrm{CD}^{+}$cells, and positive percentages are shown.

Statistics. Two-tailed Student's $t$ test was used to calculate statistical significance for differences between groups. $P \leq 0.05$ was considered statistically significant.

1. Schon, M.P., and Boehncke, W.H. 2005. Psoriasis. N. Engl. J. Med. 352:1899-1912.

2. Zenz, R., et al. 2005. Psoriasis-like skin disease and arthritis caused by inducible epidermal deletion of Jun proteins. Nature. 437:369-375.

3. Cook, P.W., Brown, J.R., Cornell, K.A., and Pittelkow, M.R. 2004. Suprabasal expression of human amphiregulin in the epidermis of transgenic mice induces a severe, early-onset, psoriasis-like skin pathology: Expression of amphiregulin in the basal epidermis is also associated with synovitis. Exp. Dermatol. 13:347-356.

4. Lowes, M.A., Bowcock, A.M., and Krueger, J.G. 2007. Pathogenesis and therapy of psoriasis. Nature. 445:866-873.

5. Groves, R.W., et al. 1996. Inflammatory and hyperproliferative skin disease in mice that express elevated levels of the IL-1 receptor (Type I) on epidermal keratinocytes. Evidence that IL-1inducible secondary cytokines produced by keratinocytes in vivo can cause skin disease. J. Clin. Invest. 98:336-344.

6. Xia, Y.-P., et al. 2003. Transgenic delivery of VEGF to mouse skin leads to an inflammatory condition resembling human psoriasis. Blood. 102:161-168.

7. Hong, K., Chu, A., Ludviksson, B.R., Berg, E.L., and Ehrhardt, R.O. 1999. IL-12, independently of IFN\{gamma\}, plays a crucial role in the pathogenesis of a murine psoriasis-like skin disorder. J. Immunol. 162:7480-7491.

8. Chan, J.R., et al. 2006. IL-23 stimulates epidermal hyperplasia via TNF and IL-20R2-dependent mechanisms with implications for psoriasis pathogenesis. J. Exp. Med. 203:2577-2587.

9. Zheng, Y., et al. 2007. Interleukin-22, a TH17 cytokine, mediates IL-23-induced dermal inflammation and acanthosis. Nature. 445:648-651.

10. McKenzie, B.S., Kastelein, R.A., and Cua, D.J. 2006. Understanding the IL-23-IL-17 immune pathway. Trends Immunol. 27:17-23.

11. Harrington, L.E., et al. 2005. Interleukin 17-producing CD4+ effector $\mathrm{T}$ cells develop via a lineage distinct from the $\mathrm{T}$ helper type 1 and 2 lineages. Nat. Immunol. 6:1123-1132.

12. Park, H., et al. 2005. A distinct lineage of CD4 T cells regulates tissue inflammation by producing interleukin 17. Nat. Immunol. 6:1133-1141.

13. Liang, S.C., et al. 2006. Interleukin (IL)-22 and IL-17 are coexpressed by Th17 cells and cooperatively enhance expression of antimicrobial peptides. J. Exp. Med. 203:2271-2279.

14. Wolk, K., et al. 2004. IL-22 increases the innate immunity of tissues. Immunity. 21:241-254.

15. Boniface, K., et al. 2005. IL-22 inhibits epidermal differentiation and induces proinflammatory gene

\section{Acknowledgments}

We thank R. Zollner, X. Tan, R. Karim, J. Wright, S. Olland, G. Yan, D. Taylor, and K. Lam for preparing the antibodies and the cytokines. We also thank E. Grady and J. Jimenez for their excellent technical support in tissue collection and L. Mason, J. Cai, and B. Carito for histological and immunohistochemical slide preparation and staining.

Received for publication July 13, 2007, and accepted in revised form November 14, 2007.

Address correspondence to: Lynette A. Fouser, Wyeth Research, 87 Cambridge Park Drive, Cambridge, Massachusetts 02140, USA. Phone: (617) 665-5565; Fax: (617) 665-5584; E-mail: 1fouser@ wyeth.com. expression and migration of human keratinocytes. J. Immunol. 174:3695-3702.

16. Wolk, K., et al. 2006. IL-22 regulates the expression of genes responsible for antimicrobial defense, cellular differentiation, and mobility in keratinocytes: a potential role in psoriasis. Eur. J. Immunol. 36:1309-1323.

17. Schon, M.P., Detmar, M., and Parker, C.M. 1997. Murine psoriasis-like disorder induced by naive CD4+ T cells. Nat. Med. 3:183-188.

18. Dejaco, C., Duftner, C., Grubeck-Loebenstein, B., and Schirmer, M. 2006. Imbalance of regulatory $T$ cells in human autoimmune diseases. Immunology. 117:289-300

19. Sakaguchi, S., Setoguchi, R., Yagi, H., and Nomura, T. 2006. Naturally arising Foxp3-expressing $\mathrm{CD} 25+\mathrm{CD} 4+$ regulatory $\mathrm{T}$ cells in self-tolerance and autoimmune disease. Curr. Top. Microbiol. Immunol. 305:51-66.

20. Gottlieb, A.B., Luster, A.D., Posnett, D.N., and Carter, D.M. 1988. Detection of a gamma interferon-induced protein IP-10 in psoriatic plaques. J. Exp. Med. 168:941-948.

21. Gottlieb, A.B., et al. 2005. TNF inhibition rapidly down-regulates multiple proinflammatory pathways in psoriasis plaques. J. Immunol. 175:2721-2729.

22. Arican, O., Aral, M., Sasmaz, S., and Ciragil, P. 2005. Serum levels of TNF-alpha, IFN-gamma, IL-6, IL-8, IL-12, IL-17, and IL-18 in patients with active psoriasis and correlation with disease severity. Mediators Inflamm. 2005:273-279.

23. Wolk, K., and Sabat, R. 2006. Interleukin-22: A novel T-and NK-cell derived cytokine that regulates the biology of tissue cells. Cytokine Growth Factor Rev. 17:367-380.

24. Charles, P., et al. 1999. Regulation of cytokines, cytokine inhibitors, and acute-phase proteins following anti-TNF-\{alpha\} therapy in rheumatoid arthritis. J. Immunol. 163:1521-1528.

25. Austin, L.M., Ozawa, M., Kikuchi, T., Walters, I.B., and Krueger, J.G. 1999. The majority of epidermal $\mathrm{T}$ cells in Psoriasis vulgaris lesions can produce type 1 cytokines, interferon-gamma, interleukin2 , and tumor necrosis factor-alpha, defining TC1 (cytotoxic T lymphocyte) and TH1 effector populations: a type 1 differentiation bias is also measured in circulating blood $\mathrm{T}$ cells in psoriatic patients. J. Invest. Dermatol. 113:752-759.

26. Chang, J.C.C., et al. 1994. CD8+ T cells in psoriatic lesions preferentially use T-cell receptor V\{beta\}3 and/or V\{beta\}13.1 genes. Proc. Natl. Acad. Sci.U.S. A. 91:9282-9286.

27. Gudjonsson, J.E., Johnston, A., Dyson, M., Valdimarsson, H., and Elder, J.T. 2007. Mouse models of psoriasis. J. Invest. Dermatol. 127:1292-1308.
28. Kim, J.M., Rasmussen, J.P., and Rudensky, A.Y. 2007. Regulatory T cells prevent catastrophic autoimmunity throughout the lifespan of mice. Nat. Immunol. 8:191-197.

29. Chen, W., et al. 2003. Conversion of peripheral $\mathrm{CD} 4+\mathrm{CD} 25$ - naive $\mathrm{T}$ cells to $\mathrm{CD} 4+\mathrm{CD} 25+$ regulatory $\mathrm{T}$ cells by TGF- $\{$ beta $\}$ induction of transcription factor Foxp3. J. Exp. Med. 198:1875-1886.

30. Langrish, C.L., et al. 2004. IL-12 and IL-23: master regulators of innate and adaptive immunity. Immunol. Rev. 202:96-105.

31. Muhl, H., and Pfeilschifter, J. 2003. Anti-inflammatory properties of pro-inflammatory interferon[gamma]. Int. Immunopharmacol. 3:1247-1255.

32. Willenborg, D.O., Fordham, S.A., Staykova, M.A., Ramshaw, I.A., and Cowden, W.B. 1999. IFN\{gamma is critical to the control of murine autoimmune encephalomyelitis and regulates both in the periphery and in the target tissue: a possible role for nitric oxide. J. Immunol. 163:5278-5286.

33. Kauffman, C.L., et al. 2004. A phase I study evaluating the safety, pharmacokinetics, and clinical response of a human IL-12 p40 antibody in subjects with plaque psoriasis. J. Investig. Dermatol. 123:1037-1044.

34. Krueger, G.G., et al. 2007. A human interleukin$12 / 23$ monoclonal antibody for the treatment of psoriasis. N. Engl. J. Med. 356:580-592.

35. Chaudhari, U., et al. 2001. Efficacy and safety of infliximab monotherapy for plaque-type psoriasis: a randomised trial. Lancet. 357:1842-1847.

36. Toichi, E., et al. 2006. An anti-IL-12p40 antibody down-regulates type 1 cytokines, chemokines, and IL-12/IL-23 in psoriasis. J. Immunol. 177:4917-4926.

37. Cameron, A., Kirby, B., Fei, W., and Griffiths, C. 2002. Natural killer and natural killer-T cells in psoriasis. Arch. Dermatol. Res. 294:363-369.

38. Sano, S., et al. 2005. Stat3 links activated keratinocytes and immunocytes required for development of psoriasis in a novel transgenic mouse model. Nat. Med. 11:43-49.

39. McMahon, E.J., Bailey, S.L., Castenada, C.V., Waldner, H., and Miller, S.D. 2005. Epitope spreading initiates in the CNS in two mouse models of multiple sclerosis. Nat. Med. 11:335-339.

40. Braff, M.H., Bardan, A., Nizet, V., and Gallo, R.L. 2005. Cutaneous defense mechanisms by antimicrobial peptides. J. Invest. Dermatol. 125:9-13.

41. Braff, M.H., and Gallo, R.L. 2006. Antimicrobial peptides: an essential component of the skin defensive barrier. Curr. Top. Microbiol. Immunol. 306:91-110.

42. Li, J., et al. 2004. Temporal associations between interleukin 22 and the extracellular domains of IL-22R and IL-10R2. Int. Immunopharmacol. 4:693-708. 